\title{
Ecovillage foodscapes: zooming in and out of sustainable food practices
}

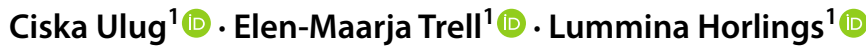

Accepted: 21 April 2021 / Published online: 29 April 2021

(c) The Author(s) 2021

\begin{abstract}
This article uses foodscapes as a lens to explore the potential of ecovillages' food practices towards enhancing sustainable food systems. Ecovillages are collective projects where members attempt to integrate sustainability principles into daily community life. In these communities, food acts, not only as an element of social life, but also as a venue through which to interact with mainstream food systems and society. Yet, how food practices at ecovillages contribute to sustainable food systems remains vague. This article proposes foodscapes, as a lens, for exploring the sustainability potential of place-based food practices in ecovillages, while also directing attention to how these practices intersect with networks at broader social and spatial scales. It asks, how can we better understand and draw from sustainable food practices, when considering these as both, place-based and relational? And what is the potential and the role of ecovillage communities to contribute to broader sustainable food system change? Drawing on ethnographic and food mapping methods, the article explores selected food practices at three ecovillage communities in the United States. Using social practice theory for "zooming in" on place-based practices and "zooming out" to examine relational networks, we investigate how these communities create internally sustainable food systems, while externally bridging themselves with broader urban and rural communities. Through viewing ecovillage food practices as place-based and relational, we develop a broader and spatially-focused understanding of food system sustainability.
\end{abstract}

Keywords Foodscapes $\cdot$ Ecovillages $\cdot$ Sustainable food systems $\cdot$ Social practice theory $\cdot$ Intentional communities

\begin{tabular}{ll}
\multicolumn{2}{l}{ Abbreviations } \\
CRSP & Cooperative Resources and Services Project \\
FPM & Food processing manager \\
IC & Intentional community \\
LA & Los Angeles \\
LAEV & Los Angeles Eco-Village \\
SPT & Social practice theory \\
ZK & Zhankoye
\end{tabular}

Ciska Ulug

c.r.ulug@ rug.nl

Elen-Maarja Trell

e.m.trell@ rug.nl

Lummina Horlings

l.g.horlings@ @ug.nl

1 Department of Spatial Planning and Environment, Faculty of Spatial Sciences, University of Groningen, Postbus 800, 9700 AV Groningen, The Netherlands

\section{Introduction}

The urgency to transition to a more sustainable food system is well acknowledged among scholars (De Schutter et al. 2019; Firth et al. 2011; Pudup 2008; Vivero-Pol et al. 2019). This has been pointed to as failings in the current globalized and industrialized food system span across sectors in society (Madrigal 2017; Nestle 2002; Wingeyer et al. 2017), resulting in unsustainable behavior that prioritizes efficiency and high-profit margins over care for local communities and environments (Morgan and Sonnino 2010). For consumers, consequences of a more industrialized food system include less trust and greater exposure to high-calorie and lownutrient foods, while for producers this means heavy investments and complying with standardized regulations in order to access markets (De Schutter et al. 2019; Renting et al. 2003). Many authors (e.g. Feagan 2007; Swagemakers et al. 2019) identify the need to reconnect food better to place in order to move towards more sustainable food systems. In this paper we focus on the role of ecovillages in their attempts of shifting in the direction of sustainable food systems. Such 
communities can be considered flagship contexts where sustainability and care for place in relation to food production, among other aspects of community living, take center stage.

Ecovillages are collective settlements that attempt to incorporate sustainable practices as an integral part of daily life, focusing on sustainable community and environmental development (Gillman 1991). This, in addition to how these communities are connected to and embedded in place, make them especially relevant for sustainable food system development. While Brombin (2015) demonstrates food to be valuable within ecovillage communities to "create new forms of sustainability" (p. 469), Ergas (2010) emphasizes ecovillages' potential for generating external sustainability impacts, around urban environmental action. Ecovillages, which are considered advanced in place-sensitive sustainable food practices, could provide insight into how to cultivate innovative sustainable food practices within communities and at a greater scale. As Brombin (2015) explicates, in such communities, food practices are examples of the "way in which the values linked to the idea of sustainability and selfsufficiency translate into concrete practices" (p. 475). The central questions addressed in this paper are: how can we better understand and draw from sustainable food practices, considering these as both, place-based and relational? And what is the potential and the role of ecovillage communities to contribute to sustainable food system change?

Sustainable food systems are characterized as food systems that prioritize environmental, social, and economic health, through connecting producers and consumers, reducing harmful external inputs, and promoting affordability and accessibility throughout the food chain (Blay-Palmer and Koc 2010; Feenstra 2002). Importantly, sustainable food systems emphasize a connection to place (Feagan 2007; Wiskerke 2009), where "a place-based approach...implies going beyond the "local"' (Swagemakers et al. 2019, p. 192). A sustainable food system could be founded upon relative social and spatial connections, able to initiate change beyond its local context, and therefore consisting of food practices that are place-based and relational (Sonnino et al. 2016). A relational approach is necessary to understand how practices, performed in a certain location, have influence beyond those geographical boundaries and result in sustainability impacts at different scales. Relationality in sustainable food systems can materialize via trans-local governance (Moragues-Faus and Sonnino 2019), or metabolic flows across space (Kasper et al. 2017). In order to understand the potential of ecovillages, we specifically employ and combine two core components, which link to characteristics of sustainable food systems - care for place and relationality. Those core components are: foodscapes and social practice theory.

In this paper we connect the concept of foodscapes to social practice theory (SPT), contributing to theoretical discussions of the place-based and relational nature of sustainable food systems (e.g. Kasper et al. 2017; Sonnino et al. 2016; Wegerif and Wiskerke 2017). As a spatial-social lens through which to view food practices, foodscapes enables researchers to highlight how food systems can be both, place-based and relational (Johnston and Goodman 2015; Wegerif and Wiskerke 2017). When highlighting these relational components alongside the place-based aspects, foodscapes encourages researchers to emphasize linkages, blurring pre-conceived categories, such as producer/consumer, conventional/alternative, and urban/rural and to embrace more "unexpected and diverse relationships" (Sharp 2017, p. 5). Sustainable food systems, which often incorporate circular and ecological flows of resources and networks, could benefit from the interconnectedness of the foodscapes lens (Heatherington 2014). Taking such a broad and holistic perspective is considered to reveal a multiplicity of dimensions and activities that shape our food system and inspire potential pathways towards sustainable change (Feenstra 2002; Sonnino and Marsden 2006).

Similar to foodscapes, SPT emphasizes broader contextual relationships (Nicolini 2012) in close combination with a focus on place-based elements of practices, such as materials and competencies (Shove et al. 2012). SPT outlines a research approach of zooming in on internal place-based (food) practices, and zooming out to show how these (food) practices connect to wider networks across scales (Nicolini 2012), to help grasp elements that shape food practices and explore their role and relevance for sustainable food system change. While foodscapes literature remains overall theoretical, in this paper we draw from SPT as an empirical entry point to help further unpack the place-based aspects and relationships in our data analysis. Following this, below we will analyze core sustainable food practices in three ecovillages and explore how these practices connect to and influence places and relations beyond the ecovillage context and implications such practices might have for food system sustainability. Applying SPT in the context of ecovillages provides in-depth insight into how sustainable patterns and innovations manifest in communities, a research gap indicated in SPT research (Daly 2017).

The data informing this paper was collected in three ecovillages in the United States in 2018: Twin Oaks in rural Virginia, Los Angeles Eco-Village, and Finney Farm in rural Washington State. After linking foodscapes with SPT below and discussing their relevance for exploring sustainable food systems and practices, we will turn to these three ecovillages to analyze one central food practice in each. The subsequent discussion will highlight the relevance of SPT and foodscapes, for researching food system sustainability as well as the potential role of ecovillage communities for sustainable food system change. 


\section{Theoretical framework: grounding foodscapes in social practice theory}

Foodscapes, drawing from the "-scapes" suffix, can be defined as a social and spatial lens in which to view foodwith attention specifically to place as well as relationality across scales (Appadurai 1990; Wegerif and Wiskerke 2017). More than relying on physical spatial data, foodscapes as an analytical lens also enables researchers to engage with the complex social world that shapes and is shaped by such spatial environments, across the food system (Miewald and McCann 2014). The place-based elements in foodscapes not only refer to the natural and built environment, but also social and cultural components, including intersecting place-based habits, practices, and traditions. Connecting these social and physical aspects make foodscapes a particularly valuable concept in discussions on sustainable food systems. Foodscapes, therefore, is operationalized in this paper as the intersection of food, people, and place (Spijker et al. 2020; Yasmeen 1996) that can be envisioned as three multi-colored spectacles that reveal an interconnected landscape of place-based food practices.

While social practice theory (SPT), similar to foodscapes, encompasses social and material elements, it, more specifically, zooms in on specific practices, emphasizing the relevance of that practice within a network of connections. Social practices consist of the "inter-connectedness of many elements - forms of bodily activities, mental activities, things and their use, background knowledge in the form of understanding, know-how and notions of competence, states of emotion and motivational knowledge" (Reckwitz 2002, p. 249). We follow from Shove et al. (2012), who specify practices to consist of materials (ex. objects and infrastructure), competences (ex. knowledge and skills), and meanings (ex. significance and motivation), with the interaction of these resulting in a practice. While SPT is useful for unpacking how practices emerge, change, and are sustained, it, above-all, reflects the values and structures that bring them into being (Shove and Walker 2010). Understanding how sustainable practices materialize in ecovillages, therefore, could contribute to understanding how to initiate a broader sustainability transformation (Feola 2015).

This paper focuses on sustainable food practices, or food practices that support a caring relationship between humans and their natural ecosystem (Hassink et al. 2002). Food practices can include a range of ways that humans handle food, including food production, processing, distribution/retail and consumption, which are, together, part of an interconnected chain (Erickson 2008; Spaargaren et al. 2013). While we recognize that the notion of sustainability is at risk for being co-opted by top-down and neoliberal interests (Blythe et al. 2018; Leitheiser and Follman 2019), we understand the term as underlining the need for a value change away from unsustainable overconsumption, resource depletion, and social and economic injustices (Vinnari and Vinnari 2014). However, we seek the concept's value beyond one place and context, and rather point our attention to cross-cutting impacts across scales. Sustainability encompasses how "social needs and welfare, and economic opportunity are integrally related to environmental limits imposed by supporting ecosystems" and, therefore, social and environmental benefits are mutually reinforcing (Agyeman et al. 2002, p. 87). In this paper, we understand (food system) sustainability to include environmental, social, and economic spaces (Blay-Palmer and Koc 2010), while also making room for political and intellectual participation (Feenstra 2002). Recognizing the role of power, we align with Swyngedouw and Heynen (2003), that socioenvironmental sustainability "are fundamentally political questions," with environmental and social struggles often intertwined (p. 910). Rather than viewing such conceptual spaces as operating separately, we conceive them to act in conjunction (Psarikidou and Szerszynski 2012), for example, small-scale production markets supporting environmental practices and local economies, based on opening space for consumers and producers to take action in their food system (Goodman and DuPuis 2002).

Building on this perspective, we view sustainable food systems as consisting of sustainable food practices and encompassing a broad range of relations across spaces and scales. Such practices are sensitive towards and care for their socio-environmental contexts, while the relations make visible connections and interdependencies of specific placebased resources. The sustainable food practices studied in this paper include food processing (Twin Oaks), retail/ distribution (LAEV), and production (Finney Farm) practices, and are elaborated upon in Table 2, in Sect. Methods: ethnography, in-depth interviews, and food mapping. Each category of activities involves specific actors (ex. farmers or consumers), with certain resources, knowledge backgrounds, routines, and patterns, which they draw upon to fulfill their respective practice (Spaargaren et al. 2013). Connecting individual food practices to a flow of activities can help understand the broader logics informing the food chain as interconnected. Following from this, we highlight the relevance of practices being relational and thus "understood as part of a nexus of connections" (Nicolini 2012, p. 229). The idea of an "organized nexus" echoes Schatzki (1996), who views practices as coordinated doings and sayings (Warde 2013). Through repeated performances by individuals, such actions are reinforced and sustained (Schatzki 1996), and through social organization and coordination, practices 
become intertwined with their social contexts (Warde 2013). To explore this so-called interconnected nexus, Nicolini (2012) details an approach that involves "zooming in" to document the dynamics and effects of local practices, and "zooming out" to make sense of these practices and translocal interconnections.

However, food practices, specifically, could be considered "weakly organized and weakly regulated", meaning, disorganized and subject to unexpected fluctuations (Warde 2013 , p. 27). Foodscapes, however, promotes a focus on interdependent food practices, rather than one, e.g. consumption (Winson 2004), to highlight how food practices are dynamic (Panelli and Tipa 2009). While practice theory recognizes the value of place, foodscapes more explicitly embraces how food practices occur in and are shaped by place, foregrounding place-based interactions. Moreover, "tracing" these interactions highlights the presence of networks, across scales. Focusing on the notion of foodscapes, can potentially help understand changing social and spatial practices around food, especially in attempts to transition to sustainable food systems (Grin 2011; Shove and Walker 2010). Building upon Nicolini (2012), this research applies foodscapes as a lens which highlights the relevance of both "zooming in" on place-based food practices and "zooming out" on relational networks. This aligns with the core ideals embedded in sustainability as a concept, to not only support immediate social-ecological environments, but also wider communities (Horlings 2018). Furthermore, exploring the ways sustainable food practices can be simultaneously place based and relational helps to understand their relevance and role in food system change. To explore the foodscapes of ecovillages, we will zoom in on and zoom out of selected central food practices at ecovillage communities with the aim to explore how such practices contribute to sustainable food systems.

\section{Zooming in on place-based sustainable food practices}

Through "zooming in" on sustainable food practices at the ecovillages, this paper will first explore their place-based characteristics, which include physical-material elements (e.g. localized plant varieties and seasonal production), as well as social relations (e.g. local economies and knowledge, self-reliance).

Our analysis highlights the physical elements through place-based or "nested" resources that exist in a certain spatial context, for example where food is grown (Wegerif and Wiskerke 2017). However, to acknowledge that place is more than the local scale (Born and Purcell 2006; Kenis and Matthijs 2014), we emphasize social relations and the relational aspects as part of the place-based characteristics of foodscapes. Therefore, we understand place as a combination of physical and social components, including a collection of different values, meanings, relations, and interactions (Massey 1991). Social relations are highlighted through actors and actions in food practices. Food is, after all, a material substance we acquire preferences for and learn about through doing (Carolan 2011). Furthermore, practices are not simply created, rather emerge and are established in cultural contexts (Warde 2013).

Our foodscapes analysis foregrounds social and cultural contexts embedded in food practices. Foodscapes can be seen as shaped by cultural, political, and social practices, which intersect with the material environment (Adema 2007; Johnston and Goodman 2015). Johnston and Goodman (2015) emphasize this multiplicity, defining foodscapes to include "cultural spaces and practices of food as well as the material realities" (p. 2). Foodscapes connects to the physical-material qualities of food practices, through foregrounding the contexts where food is produced, distributed, and consumed (Johnston and Goodman 2015). This is seen, for example, when food, itself, is the research subject with "food biographies" or "following food" (Cook et al. 2006; Smith and Jehlička 2007), tracing food products' histories and origins. As indicated above, foodscapes' intertwining social and material elements are valuable for connecting to "a deep commitment to a particular place" and contributing to sustainable food systems (Heatherington 2014, p. 24). When "zooming in", this paper uses foodscapes, as a lens to draw out the place-based qualities of food, through emphasizing social relations and materials in food practices, as well as grounding insights and entry points towards sustainable possibilities.

\section{Zooming out of relational sustainable food practices}

Through "zooming out" and viewing sustainable food practices in their embedded contexts, we focus on their relational aspects. Using foodscapes as a lens, we underscore the necessity to think through potential opportunities, connections, and actors across the food system and bring to light relational elements embedded in food in order to better understand food system sustainability. Zooming out of food practices enables researchers to extend beyond food as a place-based phenomenon, with the assumption that such focus alone is not sufficient for a transformation towards sustainable food systems.

Highlighting relational interconnections in food practices could help think through strategies for sustainable food system development. To foreground interconnections, Nicolini (2012) recommends researchers to follow a "trail of connections between practices and their products" using practice theory, which this paper will draw on through analyzing externally networked food practices (p. 219). In this paper, 
we address this by foregrounding social relations and contexts embedded in food practices.

Foodscapes is useful for such an analysis, in that "as a concept and set of practice... [it] encourages us to spatialize our analyses, drawing attention to the ways that food cultures operate and travel across different, multiple and shifting scales" (Johnston and Goodman 2015, p. 2). This definition highlights the importance of scale, also relevant for researching sustainable food practices (Eakin et al. 2017). Foodscapes simultaneously encompass the macro (global), meso, and micro scales (Mikkelson 2011), through coexisting at these different scales, and being interconnected and shaped by activities that occur at these scales (Wegerif and Wiskerke 2017). Interconnections in foodscapes can be analyzed, for example, through the transmission of Traditional Food Knowledge (TFK), which "can support the continuity of cultural heritage through time and place" (Kwik 2008, p. 62 ). The relational framing is especially appropriate in ecovillage communities, where food production systems strongly support and are connected to local consumption needs. We employ a foodscapes lens to bring to light how ecovillages connect to and influence wider landscapes through their food practices. Thus, through the foodscapes perspective we emphasize food practices as interdependent components in the food system, working together.

\section{Research context and methods}

\section{Ecovillage context and case selection}

Ecovillages are considered "human-scale, full-featured settlements, in which human activities are harmlessly integrated into the natural world, in a way that is supportive of healthy human development and can be successfully continued into the indefinite future" (Gilman 1991, p. 10). Considered as a type of intentional community (IC), ecovillages more specifically focus on environmental sustainability (Litfin 2014; Meijering et al. 2007; Wagner 2012). ICs have historically attempted to retreat from society, in order to maintain community ideals, and self-sustaining and autonomous practices (Ergas 2010; Kanter 1972; Meijering et al. 2007). Despite their earlier desires to be physically and/or psychologically isolated (Ergas 2010; Meijering et al. 2007; Schehr 1997), ecovillage communities also interact with and, to some extent, depend on neighboring communities and services. Thus, while wishing to escape society and dominant, often unsustainable, ways in the mainstream, ecovillages are simultaneously grounded in their broader social and physical environment.

While often romanticized as a place to generate solutions to global environmental change, ecovillages have been criticized as not sufficiently addressing radical transformations, especially in regards to social environmental justice, for example, reproducing white privilege or failing to tackle dismantling market capitalism (Chitewere 2010; Fotopoulos 2000). Chitewere (2010) specifically notes that "instead of a focus inwards on personal or neighborhood concerns to be sustainable, ecovillages must focus their lens outward into the larger community" (p. 339). More recently, ecovillages today have been documented as more willing to embrace their relationships with wider communities, especially through attempts to "[experiment] with new forms of living and transferring this knowledge and experience to other contexts" (Avelino and Kunze 2009, p. 21).

This research explores food practices at three ecovillages in the USA. The United States was chosen as a research context due to its unique social and spatial diversity. A country facing declining rural regions (Swenson 2019) and one of the deepest political polarizations in decades (Pew Research Center 2019) has seen diversity and inequality magnified by place. This research includes three spatially distinct sitesthe conservative rural South, the progressive urban Southern California, and the environmentalist rural Cascadia—and attempts to highlight how all three undertake diverse endeavors toward food sustainability in their local community.

Ecovillage communities were selected using two prominent online directories - the Fellowship for Intentional Community (FIC) and the Global Ecovillage Network (GEN). ${ }^{1}$ Factors considered include that the ecovillage was established, in terms of members, longevity, and web presence, to ensure an active community (Boyer 2015). An established community is essential as $90 \%$ of ecovillages disband in the first 5 years (Christian 2003). The prominence of community food practices was also crucial for site selection, including growing their own food and facilitating interactions with outside communities through food practices.

This search identified 21 relevant ecovillages, from which 3 were selected, based on the above criteria and their willingness to participate. The three selected were diverse in terms of size, location, and include rural and urban contexts, as illustrated in Table 1. A diverse selection highlights different narratives and meanings of food in place. While the urban case might stimulate more networking connections, acquiring locally grown food in the Los Angeles metropolis poses complications. The opposite could be said about rural communities-regarding connections across scales and community roles in initiating rural sustainable action. Characteristics of these communities and food practices are elaborated upon below.

\footnotetext{
${ }^{1}$ See FIC Communities directory, available at: https://www.ic.org/ directory/ and GEN directory, available at: https://ecovillage.org/ projects/.
} 
Table 1 List of Ecovillage communities

\begin{tabular}{llll}
\hline Characteristics & Twin Oaks & Los Angeles Ecovillage & Finney Farm \\
\hline Location & Virginia, rural & Los Angeles, CA, urban & Washington State, rural \\
Founding year & 1967 & 1993 & 1989 \\
Number of residents & 100 & 40 & 8 (Plus volunteers) \\
Other characteristics & $\begin{array}{l}\text { Income sharing, operates } \\
\text { tofu and hammock busi- } \\
\text { nesses }\end{array}$ & $\begin{array}{l}\text { Located in diverse urban neighborhood, estab- } \\
\text { lished food-sharing hub for residents and non- } \\
\text { residents }\end{array}$ & $\begin{array}{c}\text { Initiates food justice education } \\
\text { programs and infrastructure in rural } \\
\text { community }\end{array}$ \\
\hline
\end{tabular}

\section{Twin Oaks: community-supported tofu and gardening}

Located in rural Virginia, Twin Oaks is an intergenerational, egalitarian income-sharing commune. In exchange for working $42 \mathrm{~h}$ a week at the community's income-earning and domestic areas, members receive everything to cover their basic needs, including food, housing, healthcare, and an allowance of $\$ 100 /$ month. Community businesses include a hammock and furniture company, wholesale seeds, and an organic, locally sourced tofu business. Twin Oaks' food infrastructure includes an extensive vegetable garden, fruit orchards, chickens, and dairy cows. Otherwise, the community purchases food from restaurant supply stores, receives food that would otherwise be thrown out, and trades with nearby communities. Twin Oaks is an example of a largescale and successful rural eco-community.

\section{Los Angeles Eco-Village: urban gardening and the Food Lobby}

Los Angeles Eco-Village (LAEV) is located in one of LA's densest urban neighborhood, Koreatown. This community utilizes its urban setting to act as a demonstration and incubation space for community organizations and projects, including a consumer food co-op. Other food practices at LAEV include organic fruit trees and vegetable gardens, beekeeping, chickens, and weekly community potlucks. LAEV provides insight into sustainable food practices in denser urban ecovillages.

\section{Finney Farm: rural food justice community programs}

Finney Farm is a self-described anarchist group in rural Washington state. The collective purchased their land in the early-1990s and is now home to eight residents and a revolving door of volunteers and interns. This community supports nearby rural communities by strengthening rural home-production and processing capacities and hosting an established volunteer program and food workshops. Though the community has been offered opportunities to grow in size, they remain intentionally small, in order to conserve their 90 acres (36.4 ha) of second-growth forest. Finney
Farm is an example of knowledge sharing in small-scale collectives.

\section{Methods: ethnography, in-depth interviews, and food mapping}

This study takes an in-depth, qualitative approach, employing ethnographic methods. Ethnographic studies seek to understand daily lives of participants, also participating in the same daily rhythms, through participant observation (Hesse-Biber and Leavy 2004). Participating in daily community practices provides "on the ground" insight into the communities' food systems and the social structures surrounding them, making "visible what is largely invisible in people's everyday practice" (Forde 2017, p. 83). Past ethnographic ecovillage research illustrates this method's suitability, notably how communities are already living an "examined existence" (Lockyer 2007, p. 152). Meaning, ecovillages and ICs operate based on what they wish to change from mainstream society, resulting in reflecting on and embedding intentional meaning into their practices.

The first author conducted participant observation and stayed in each community for 1 month. To provide transparency, she explained the research aims and intentions to all community members at the beginning of each stay. The first author also volunteered in food-oriented areas, including the gardens, kitchens, and food processing facilities. Two of the communities (Twin Oaks and Finney Farm) offer more formalized visitor and intern programs, and while LAEV does not, the ecovillage still offers housing for researchers and interns. Observations investigated food practices, including production, consumption, processing, and waste, highlighting the nexus of food, people, and place. The researcher used a field diary to document all notes, including passing occurrences, informal conversations, and personal reflections, using a semi-structured diary format to detail reflections of events and interactions.

In addition to observations, this study included 37 indepth interviews with ecovillage residents and visitors. This includes 16 at Twin Oaks, 11 at LAEV, and 10 at Finney Farm, with participants ranging from 17 to 81 years old (at the time of the interview), and an average age of 43 years 
Table 2 Sustainable food practices explored in this paper

\begin{tabular}{lll}
\hline Practice researched & $\begin{array}{l}\text { Examples of similar and related (sustainable) } \\
\text { practices and initiatives }\end{array}$ & Contributions and relevance to sustainable food systems \\
\hline Food processing (Twin Oaks) & - Fermentation & - Facilitates eating homegrown products year round \\
& - Canning & - Autonomy from industrially processed food \\
& - Dehydration & - Fewer artificial additives \\
& & - Prevents food waste \\
Cooperative food retail and distri- & - Food cooperatives & - Collective purchasing \\
bution (LAEV) & - Community supported agriculture (CSA) & - Direct purchasing from local/small holder farmers \\
& - Food hubs & - Limits food miles \\
Seed saving (Finney Farm) & - Seed libraries & - Encourages democratic decision making \\
& - Seed banks & - Protects heirloom varieties \\
& - Seed exchanges & - Promotes agricultural biodiversity \\
& & - Minimizes reliance on industrial seeds
\end{tabular}

(across all communities). Also across all communities, 16 interviewees identified as male (43\%), 17 as female (46\%), 2 as agender or neutral (5.5\%) and two who preferred not to answer $(5.5 \%)$. Participants were selected based on their role in the community, prioritizing those involved in the food areas (ex. garden managers, food buyers) and in leadership or organizing roles (board members, founders, longterm members). While many interviewees were identified by tips from other participants, interviews were open to all who offered. All interviewees participated voluntarily and were given and signed informed consent forms. All names are changed to pseudonyms, with the exception of Lois, the founder of LAEV, who requested her name be used. Interviews were especially useful to learn how participants viewed their food system, its role in their community, and external connections and networks, which were not clear from observations.

To kindle discussions of community food practices, visual mapping methods were also implemented. Food-mapping methodologies have been used by foodscape researchers to foreground place-based interactions (Burgoine and Monsivais 2013). Mapping in food research initiates participants to reflect upon and broaden their food system perspective, while simultaneously mapping food facilities, stimulating a sensorial and spatial awareness of food (Wight and Killham 2014). This research conducted mental mapping exercises by presenting participants with a printed community map (either provided by the community or drawn by the researcher) and asking them to identify unique food practices, to draw out place-based activities. Mental mapping provides insight into how daily practices connect to place, the relation between these places, and what is shared among individuals (Trell and van Hoven 2010). This activity functioned as a prop to guide interviews, asking how communities engage with food, as well as personal perspectives of the role food plays in the community.

While the data collection witnessed a wealth of sustainable food practices, within each ecovillage we were able to identify one sustainable food practice, which appeared to be central within the community itself as well as have a central function forming a basis for their food-related interactions beyond the community. We prioritized food practices that interview participants recognized as central to community life and their surrounding environment. At Finney Farm, all participants identified seed saving to be central to the community's social practices and strongly embedded in their environment. For interviewees at LAEV, the food lobby was a leading and innovative food practice in the community, especially for aligning with the community's sustainability ambitions. Food processing at Twin Oaks recurred and was dominant in participants' food maps through the ways it intertwined and linked with the majority of other community food practices (ex. gardening and cooking). Table 2 lists the central sustainable food practices and their connections to sustainable food systems.

Interview and observation data was first analyzed based on codes that focused on place-specific and externally-connected food practices (including production, processing, consumption, and waste-related practices). Following the first round of coding, the first author identified themes based on literature on foodscapes and SPT. This includes the social and spatial elements (ex. the role of place), as well as the role of knowledge, materials, and meaning in each selected food practice (Shove et al. 2012).

\section{Ecovillages: building internally sustainable and externally networked food systems}

\section{Food processing at Twin Oaks: a platform for external collaboration}

Industrial food processing results in artificial additives in our food supply (Geyzen et al. 2012) and the deskilling of consumers throughout the food chain (Kwik 2008). For those producing raw food materials on a small scale, processing 
facilitates eating homegrown products year-round, and increases autonomy and self-reliance in a sustainable system of provisioning. Though technological innovations in food processing have, arguably, contributed to food becoming a global commodity, small-scale food processing and preservation supports sustainable food systems.

At Twin Oaks, food processing is closely intertwined with other food practices in the community (e.g. dependent on garden produce and consumption habits) and is an example of a holistic approach, relying on other activities throughout the food chain. Twin Oaks engages in a range of food processing practices, including deep freezing, fermentation, canning, and dehydration, to help extend the life of garden produce.

\section{Zooming in: spatial and social components of food processing}

At Twin Oaks, place-based knowledge is necessary for food processing, to ensure the continuity of this community practice. Food processing competencies are passed from one Food Processing Manager (FPM) to the next. In the community, labor is divided into different work areas, led by management teams, in domestic and income-earning areas. The FPM oversees processing activities and passes on their experience through word-of-mouth, written logs, and archived materials. Jessica, the current FPM, notes:

[The previous manager] had written up in the food processing binder ... "Canning tomatoes at Twin Oaks" ... when we were dealing with these 25 bucket harvests, it was great to just have these [local instructions] ... as opposed to looking that up online and [having] to multiply by 100 at least.

Feeding over 100 people at Twin Oaks underscores how knowledge and practices must be adapted for place. Having such knowledge in the "minds of a group's collective memory" highlights the role of the ecovillage collective, in perpetuating such practices, and preventing deskilling seen in contemporary food systems (Kwik 2008, p. 63). It is thus necessary to maintain knowledge for carrying such practices out. If knowledge is not properly exchanged internally, competencies are potentially lost (noted by interviewees), putting ecovillages at risk for mainstream deskilling.

While food processing must "take place" at Twin Oaks, unlike many work areas, the processing lacks its own physical workspace, which is a cited frustration for the FPM. The FPM must, instead, coordinate with cooks, to reserve the industrial-scale kitchen of the main community house, Zhankoye, or ZK. Food processing at Twin Oaks, therefore requires both a spatial and temporal synchronicity. While the practice could be vulnerable to tenuous fluctuations, the flexible use of physical space highlights the resourcefulness of the community.

The central location of ZK (see Fig. 1a) facilitates different elements in the food system to work together, also benefitting food processing practices. ZK also houses many community food practices and activities and is embedded within the community's food landscape (among orchards and grazing pastures, in Fig. 1b). For food processing, this means shorter traveling distances between facilities and working groups. The centrally located food infrastructure stresses how place can enable integrating sustainable food practices with community life.

Changes in Twin Oaks' food processing practices shed light on meanings of food in the community. Twin Oaks previously grew and canned their own tomatoes, which interviewees perceived as being more autonomous and reliant on their own production systems. However, as a result of less garden and processing labor, they halted tomato production and now purchase commercial sauce. As stated by Timothy, a community member for 23 years:

Some people are like "why don't we have local tomato sauce?" And I'm like "why don't we grow our own tomatoes so we don't have to buy tomato sauce?" ... The cost of trying to buy organic tomato sauce, which we use a lot of, is prohibitive.

Timothy emphasizes the contradiction-community members request organic products over the current "conventional" sauce, to align with their values around sustainability and self-reliance. However, by purchasing the "more sustainable" items, they must exchange money and still rely on the mainstream economic systems Twin Oaks attempts to avoid. Beginning to rely on store bought products, Twin Oaks witnesses, what members dub, the "capitalist washing" of their community, a trend which extends beyond the community's food system, for example, also into the community's use of modern technology. Members cited changes in their food system (also including the increased purchasing and consumption of factory farmed meat) when expressing fears that their community values are becoming diluted by an encroaching mainstream society. The growing tendency to outsource resources could be evidence of Twin Oaks' diminishing connection with their food system and their place-based relationships.

\section{Zooming out: from trash to treasure}

Through connections made with the neighboring community, Twin Oaks members initiated a "food rescuing collective," where they collaborate with other ICs and the local food bank to impact food sustainability on a broader scale. Realizing the local foodbank is oversupplied with many almost-expired supermarket donations, a Twin Oaks 

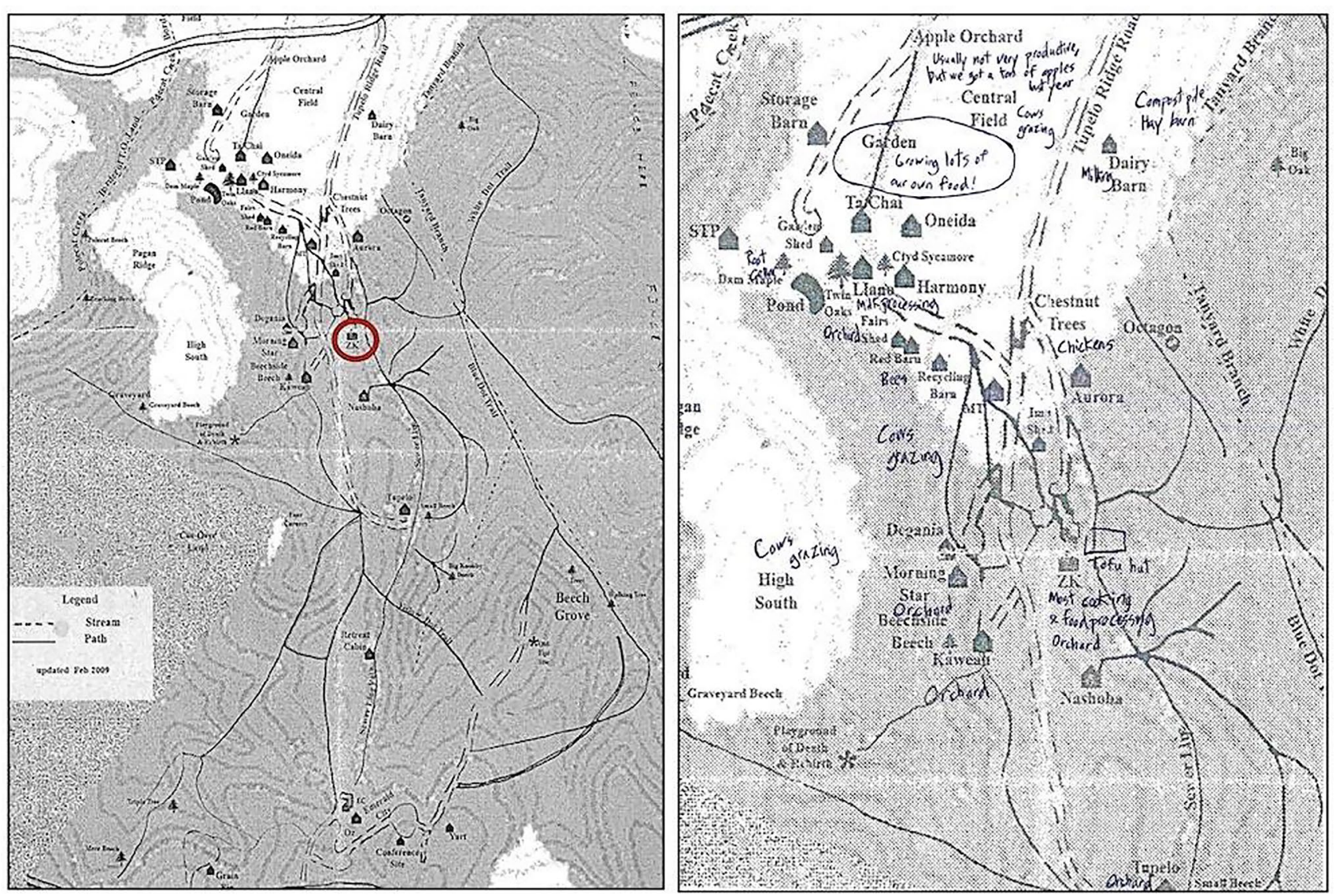

Fig. 1 a (Left) whole community, including the main community kitchen at ZK (circle in middle), and $\mathbf{b}$ food activities in the central community area, as annotated by interview participant, Mary

member, Paul, coordinated with the foodbank to intercept and re-distribute the food to other rural ICs in the county. To prevent spoilage, this community network collectively processes and re-distributes the excess, applying the rationalities of Twin Oaks' internal food processing practices to a broader scale. Mary, a librarian, farmer, mom, and 17 year-long member of Twin Oaks describes:

We got 8 pallets of strawberries. A smaller group couldn't possibly do anything with that but ... [the FPM] organized this big food processing effort and people processed strawberries around the clock and we had frozen strawberries and strawberry pies and jams and strawberry daiquiris and we had this whole stash of them for the winter too.

Involving the whole community in these efforts supports developing, as stated by Paul, "food processing capacity[ies], internally.” He elaborates:

Often times there's a supply much greater than we can deal with immediately consuming. We're work- ing to ... draw labor from other communities ... to process food

Such collaboration is valuable for the network of starting ICs, as the surplus can "supplement their income" and provide for their basic needs, as stated by Paul. By using food that would be discarded, the initiative addresses issues of overproduction, also highlighting how ecovillages interact with industrial and global-scale food systems. Aided by the collective labor and physical infrastructure available, this partnership builds upon place-based resources and further strengthens the network of rural ICs and experiments of collective and sustainable living. This initiative demonstrates how food practices benefit the immediate community, while providing resources for building capacities at a greater scale.

Internal food processing practices at Twin Oaks afford capacities for external collaboration. Interviewees emphasized food processing's role in addressing community goals, including connecting to sustainable food systems, avoiding the exchange of money, and promoting autonomy and self-reliance. Outside of the community, food processing 
practices initiated by Twin Oaks members salvages surplus food, turning waste into resources, which then recirculates among external (IC) networks. This connects rural ICs, building upon local knowledge and resources, and potentially creates a web of mutual support, strengthening rural livelihoods.

\section{The Food Lobby at the Los Angeles Eco-Village: outreach for an urban resource center}

The food-related practice observed at LAEV centers around the so-called Food Lobby. Comparable to both formal and informal food cooperatives and community supported agriculture (CSA) schemes, the Food Lobby is member-operated and possible through collective purchasing power, aligning with sustainable food systems through purchasing directly from local farmers, limiting food miles, and encouraging democratic decision-making (Tremblay et al. 2019).

The Food Lobby consists of a bulk room and a weekly vegetable box. After visiting farmers' markets on Sundays, a local organic vegetable farmer delivers leftover produce, which is divided into $\$ 10$ shares. An organic distributor in Oregon supplies the bulk room, which includes staples such as grains, beans, dried fruit, nuts, and coffee (bought from local roasters). In the words of Marilyn, the Workshift Coordinator:

[At] the [conventional] store ... you see all this crap you don't need ...but... [the bulk room], is like a condensed version of the most basic necessities that have been agreed upon by everybody, so it streamlines your food experience.

As such, the bulk room is seen to represent a healthy and sustainable alternative, while also reflecting the democratically-determined selection of foods by program participants.

While the Food Lobby is open to members outside the ecovillage, all participants (who receive discounts) must volunteer to maintain low overhead costs. This project can be seen as an example of limiting wasted produce and providing also urban dwellers access to affordable local organic vegetables, connecting to environmental, economic, and social sustainability.

\section{Zooming in: spatial and social components of the Food Lobby}

The bulk store of the Food Lobby is located in a vacant apartment unit at LAEV, which previously hosted a person displaced by Hurricane Katrina. Once they departed, discussions emerged for addressing the community's own emergency preparedness, through a food supply, which the Food Lobby still embodies today. The vegetable distribution occurs in the community's communal lobby area (hence the name), which otherwise hosts meetings, conferences, and a bi-weekly Saturday tour. However, in the absence of planned events, the space often remains vacant, apart from residents' intermittent foot traffic. Sunday afternoons, the farmer delivers vegetable crates, which volunteers sort into equal shares. The sorting sessions allow for sharing experiences and knowledge, with much of the conversation centering around the vegetables themselves, for example, making zucchini bread and refrigerator pickles, and other strategies to manage the surplus. Sorting in the hallway or lobby areas illustrates, similar to Twin Oaks, a flexible use of space in ecovillages and the visibility and centrality of sustainable food practices in such communities.

The spatial and temporal moment of the bulk room store and Food Lobby initiate what many interviewees commented to be a "social scene". Both are "open" at corresponding times, when volunteers, customers, and ecovillage members are known to trickle in and informally converse in the shared spaces. Located at the building's entrance, the space enables social interactions within the initiative and for non-participating residents, arguably raising visibility and awareness of the initiative.

The Food Lobby's social components highlight how members' lifestyles, interests/values, and competencies are integral to their participation and relevant for building sustainable food systems. Members' lifestyles reinforce their participation in the program, through their food preferences and collective cooking and eating practices-which arguably also support sustainable food alternatives. Many participants, who live at LAEV or other ICs, commented that they share the weekly box, finding it's too large for one individual. Interviewees cite collective cooking, shopping, and eating practices to support the Food Lobby's collective purchasing. Thus, evidence not only suggests that collective processes support sustainable food provisioning, but also that food provisioning made available through the Food Lobby initiates collective food practices. Marilyn elaborates how personal interests and values also motivate participation, which "has to be a unique combination of someone who needs it financially, who cares about food, who cares about food justice". Issues of food justice were echoed by other interviewees, illustrating members' structural urban food access concerns that reach beyond the community. In addition to these aspects, participants also emphasized the necessity to align cooking capacities, time to cook, as well as time to pick up the box. Kelly, a LAEV resident, comments how the box's contents discourage her participation, saying "it's a very low amount of things that I get [at the Food Lobby] because it is a lot of like hippie food." "Hippie food", in this sense implies, for example, organic vegetables and whole grains, emphasizing principles of health and sustainability. According to Kaufman (2018), this notion has influenced mainstream diets since 
1960s. However, "hippie food" has, at the same time been criticized for giving an impression of moral superiority and elitism (Guthman 2003). In addition, as our interviewee Kelly points out, hippie food can be overly pragmatic and bland in taste, therefore not appealing to many customers (herself included). While access to the Food Lobby could incentivize members to expand their tastes and creative cooking aptitudes, perhaps there are also limiting factors for participation in the program, which will be elaborated upon in the following section.

\section{Zooming out: the Food Lobby's expansion potentials and limitations}

The Food Lobby fits into LAEV's attempts to "reinvent what it means to live in a city"- through living more sustainably and being a demonstration project for LA. LAEV fills the role as a demonstration project in a variety of ways, not only through the physical interventions they carry out on their own property but also their awareness-raising attempts in the neighborhood. A good example is the gray water irrigation systems in the community. LAEV organized workshops around the installation process to assist individuals to replicate the procedure in their own home. The community further fulfills their goals in relation to being a demonstration project by capitalizing on external networks and resources to incubate projects through the nonprofit Cooperative Resources and Services Project (CRSP). CRSP acts as the fiscal umbrella for social justice and environmental sustainability-based initiatives, including the LA Bicycle Kitchen, Cafecito Organico, and Greywater Action. The Food Lobby is a similar incubation project, addressing urban food access.

Interviewees hinted at goals of the Food Lobby's expansion, towards a more formalized food cooperative, implying it move to a larger and more accessible space. This ambition has, simultaneously, been criticized. Lois, the founder of CRSP and LAEV, reflects:

A lot of people [members] don't like that [the possibility of moving the Food Lobby] at all. They like the intimacy of it here. I like it too but I think that it should grow.

Lois' quote echoes contradictions at LAEV and other ecovillages-balancing desires to be autonomous and focus on their own community, with aspirations for wider influence.

The interviewees list the Food Lobby's specific product selection as a potential barrier for engagement in their central LA neighborhood, Koreatown. While aiming to offer staples, members reflect that food available could signify "hippie" or "white person" food, deterring the ecovillages' predominantly Latinx and Korean neighborhood. Corey, the Food Lobby Food Buyer, expands:
A lot of the people in the neighborhood are from Central and South America and we don't carry the foods that they like to eat, other than a few kinds of beans. So, they've tried shopping here, but it hasn't been a great experience for them.

Intentionally low costs are overshadowed by other social and cultural barriers, limiting involvement from diverse cultural backgrounds. While many consumers eat foods based on taste and familiarity, food also provides a connection with cultural and ethnic heritage (Fuster 2017), pointing to the cultural meanings of food and the relevance of its context. Interviewees also cited language and cultural differences as a reason why LAEV has difficulty involving their neighborhood. While many residents wish to engage with their community, many simultaneously hesitate at the risk of coming off as patronizing. Kelly describes:

I feel like if we reach out to our immediate neighbors and we're like "look what we're doing over here, we're a bunch of white people and we live ecologically, don't you want to do what we're doing?" It feels really condescending to me.

Sara, a LAEV resident, also remarks that she would "like to know how to form relationships with [their neighbors] first and then introduce them to the ecovillage" but feels "the best way to form that relationship would be to learn the language that they're most comfortable with." LA's encroaching gentrification was also often raised in interviews. Residents, while cognizant of the ecovillage's demographics and potential to contribute to gentrification in their neighborhood, actively attempt to counteract such forces, through offering affordable housing and bilingual education. Interviewees also described neighborhood interactions to include painting street murals with their neighbors and hosting meetings for local action groups (ex. Koreatown Popular Assembly and LA Tenets Union). These examples illustrate how LAEV is not only active in their community but also, and importantly, aware of their nuanced role in their neighborhood and in the city. At LAEV, food activism helps contribute towards their goals for establishing a platform for engagement and action in their community (which they have seen success and interest in), however, can also reveal potential blind spots, requiring members to reflect upon their own position in the community.

In sum, the Food Lobby is an example of a community developing creative and sustainable solutions for urban food provisioning (i.e. overconsumption and food access), based in collective community action. The bulk room and vegetable box limit packaging waste and enhance the wider community's access to sustainably sourced products through their collective buying power. The vegetable box provides a venue for a local farmer to sell leftover produce, reducing 
food waste. While LAEV and the Food Lobby strive to maintain an accessible product, the celebrated intimacy could discourage certain populations, and implores the question of who is this sustainable alternative for?

\section{Seed saving at Finney Farm: internal germination, external dissemination}

Saving seeds for future use protects heirloom varieties and is relevant to sustainable food systems. When a seed is not propagated, circulated, or stored properly, it risks declining germination rates and contributing to a loss of biodiversity, which is occurring at an alarming rate in a period of unsustainable industrial agriculture and climate change (Wiskerke 2009). On a local scale, community groups rally for seed diversity and sovereignty by creating seed banks, libraries, or exchanges (Helicke 2015). Seed saving at Finney Farm aligns with the above goals for building sustainable food systems through propagating seeds for their own garden use and their seed distribution outreach program, the Seed Distro.

Finney Farm began seed saving through curating their garden for their Pacific-Northwest climate-reducing external inputs and highlighting the role of place in building the community's sustainable food system. Seeds were first distributed to family and friends, and then at an annual local barter fair. Witnessing the seeds' popularity, the community up-scaled the operation, and now grow, package, and freely distribute 10,000 packages of organic, heirloom, open-pollinated seeds. Seed distribution aligns with Finney Farm's goals of community education and outreach, as stated in their bylaws, connecting seed saving to goals that extend beyond the community.

\section{Zooming in: spatial and social components of the Seed Distro}

Seed saving at Finney Farm happens in the communal garden, the community house (for drying and storage), and the barn (for drying and storage). Food practices are foregrounded in common areas. While the communal areas are open to all residents, they are most heavily trafficked by the interns and volunteers (who stay in the community house), and when residents engage in food-related tasks, such as canning and dehydrating (which also occur in the community house). However, as with the dynamic nature of the community, the use of these spaces is flexible depending on current residents and projects. These communal food spaces are integrated into the developed area of Finney Farm, in line with their "permaculture zones". Jamie, a long-term community member, who also leads many garden and seed projects, elaborates:
We really want [the gardens] all to be community centered and we want people to have to pass through that space in order to get essentially anywhere. So it's really intentional.

Through designing community and food areas with this approach, food meanings are integrated into the community landscape, raising residents' awareness of the community's food system. Christi, a long-term resident, highlights the importance of the space, saying that for "a lot of people who are drawn to being here and living here, it's just as much about the beauty and serenity of it as it is about having the space to farm". Jamie illustrates these permaculture zones when mapping community food practices (Fig. 2). Thus, seed saving's physical place foregrounds how sustainable food practices are integrated into Finney Farm's community life.

The Seed Distro connects to social activities, including knowledge sharing and communal labor. Competencies necessary for seed saving extend across the food system, and build on knowledge of other food practices, such as gardening. During her stay, the first author observed intentional teaching processes, for example, farm workers being given instructions for harvesting plants that had "gone to seed". When community members were unavailable, experienced volunteers would explain it to others, illustrating how a knowledge hierarchy facilitated efficient gardening and seed saving work. Similar to Twin Oaks, the collection and transmission of knowledge in the community proved vital for carrying out activities related to maintaining a sustainable food system. However, Richard, a Finney Farm member, emphasizes how gardening is merely one component of the community experience, stating:

We can provide everything from really sort-of hands on knowledge in the garden .... and also how critical thinking applies to that and how communication applies to that. I mean, there are just so many layers.

For me it's just a really organic experience.

Therefore, gardening and seed saving can be considered means through which the ecovillage communicates their broader ideals. Internal knowledge exchange also illustrates the community's wider impact, through teaching volunteers, who eventually depart and bring these competencies with them.

Together, Finney Farm residents package dried seeds in the wintertime, which interview participants describe as an opportunity for the community to unite. Val, who grew up on the farm, states:

If we didn't have the garden and the seed distribution thing, and all the things we do for our community, we wouldn't have our community... we wouldn't all have kinda a main goal. 
Fig. 2 Jamie's map of food practices at Finney Farm

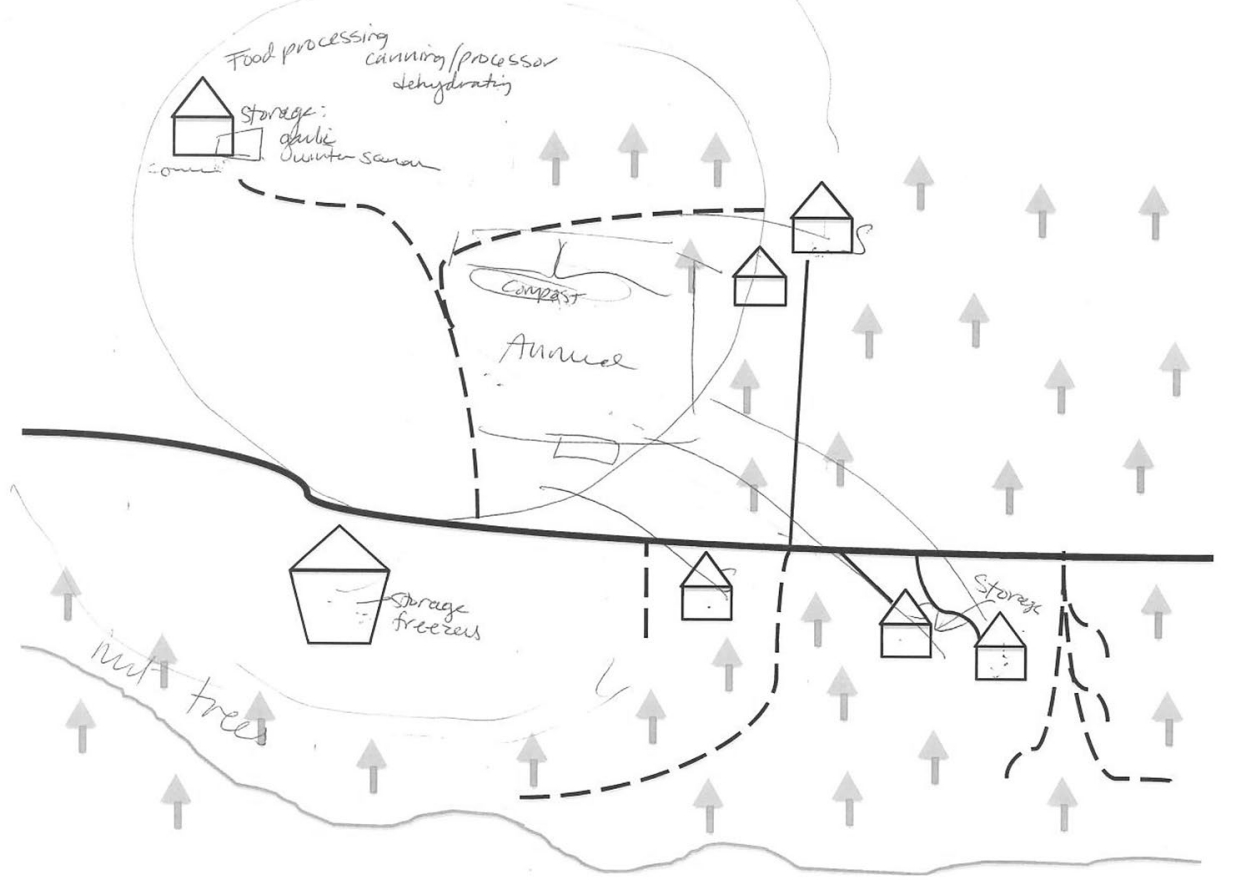

The Seed Distro addresses the underlying mission of Finney Farm and benefits residents, in contributing to community cohesion and offering an opportunity to participate in socially and environmentally responsible action.

\section{Zooming out: the Seed Distro's dissemination across scales}

When developing their operation, the community applied for and received an \$1800 grant from a local food co-opexternal funding that helped widen the scope of the project. Jamie, the program's driving force, notes that this grant, more importantly, "connected [them] with other recipients of the grant ... to make these networking connections". As a result, Finney Farms' seeds are distributed through food banks, which more efficiently connect the community with the food-insecure populations they wish to target. Widely popular, the community notes in an online promotional video "food bank recipients were frequently specific in their gratitude" otherwise "resort[ing] to dollar seed packets from Walmart that they knew were inferior". Many community residents similarly cite the value of the program for their immediate rural community, which is a USDA-designated food desert. Freely distributing seeds directly to members of the community or through institutions, Finney Farm provides an alternative to mass-produced and less locallyadapted products. Thus, resourceful networks across scales allow the community to preserve their local biodiversity, resist large seed companies, and build capacities for a placebased food system.
Finney Farm members and outside participants additionally table at events to distribute seeds and provide information about their project. As stated by Christi:

I've gone several years to that [Environmental Law conference] in a row and to meet people who were there the year before and have stories about the seeds that they've planted and friends that they've sent the seeds to that they're growing in Florida.

Residents connect the dissemination and impacts of their actions and the opportunity to participate in larger causes of seed diversity and sovereignty. Seed saving exemplifies how one action can be integral in building what Christi describes to be "its own little unique system" on a place-specific scale, while having the potential to propagate meanings of food sustainability across scales.

That being said, the values central to Finney Farm do not always align with the values held by their broader communities (ex. regarding political or religious views). Interviewees recognized that opposing values were inevitable and attempted to look past such differences unless they conflicted with their outreach projects. For example, a Finney Farm resident referenced a nearby food bank, run by a church, that required potential beneficiaries to have a private interview with the minister in order to access the food. While it was unclear what this interview exactly entailed, Finney Farm was skeptical of potential religious pressures put on by the church and did not agree with this procedure. The ecovillage still sought opportunities to support this area (finding other venues through which to distribute seeds), however, 
in this instance, the disagreement in how things should be done deterred Finney Farm from initiating a partnership with the church. This is an example of how differing values and principles could impact Finney Farms' wider networks and relationships.

Seed saving at Finney farm is valuable for residents, their rural area, and outside communities. While the physical place of Finney Farm germinates capacities in growing the seeds and involving residents, the community's collective knowledge and labor drives the project to initiate a widerscale impact. Thus, the integration of physical and social resources is integral in how the Seed Distro is based in the community and extends outwards. Dissemination, intrinsic in spreading seeds across scales, makes the practice of saving seeds an example of how internal food practices contribute to greater food system sustainability.

\section{Discussion and conclusions}

This paper sought to analyze sustainable food practices in ecovillages as both place-based and relational and to explore how such practices contribute to sustainable food systems. By using such an approach, the aim of the paper was to better understand the potential contribution of ecovillage food practices for food system sustainability. The studied food practices highlight place-based networks, resources, and knowledge, as essential for ecovillages' contribution towards sustainable food systems. When tracing ecovillages' food practices and their impacts through "zooming in" and "zooming out", we illustrated how such locally embedded practices influence sustainability within the ecovillages, while simultaneously extending and contributing to the sustainable food systems in their broader communities.

\section{Place-based and relational food practices}

One of the two core concepts informing this paper-foodscapes - enabled us to draw attention to how individual practices might simultaneously be both place-based and networked, facilitating a more nuanced analysis of ecovillage food practices. Our findings illustrate that, while ecovillage food practices emerged locally, each community also acted as a hub, initiating impact on a wider scale for their food system and community. Finney Farm exemplified how a sustainable food practice (seed saving) developed from an internal need, and, through networks and care, expanded beyond its initial local context, to provide resources to the broader community. Empirically "zooming in" and "zooming out" inspired by social practice theory (Nicolini 2012) enabled us to explore both, place and relationality, complimenting the theoretical foodscapes lens.
The relationality of food practices was largely witnessed through the dynamic connections that ecovillages sought out and built up with their neighbors and communities. Based on feedback from their wider community, ecovillages initiated tailor-made programs as solutions to unsustainable gaps they witnessed needing to be addressed. At Finney Farm, for example, residents connected their farm's seed growing capacity with their surroundings' need for fresh and healthy food access. Furthermore, established community relationships provided opportunities to expand their projects, including contacts with local and statewide community groups (i.e. food banks), other ICs, and local farmers. These connections opened possibilities for community partners to support the ecovillages' projects, while also benefiting themselves (for example, having an outlet for surplus food, or receiving free seeds). Therefore, when compared with Chiteware's (2010) critiques of communities' limited inward focus, our findings illustrate how ecovillages have evolved, to taking on greater responsibilities and actions towards social and environmental change. Through responding to mainstream activities and utilizing place-specific resources, sustainable food practices in ecovillages are dynamic and relational. Viewing food practices relationally helps trace relationships and resources, for opportunities to challenge unsustainable practices towards more sustainable alternatives.

Interactions with mainstream actors, however, were not unproblematic. At Twin Oaks, for example, several members feared that increased resource exchange with the mainstream could indicate the community succumbing to a market capitalist system, which is what many members wished to avoid. Ecovillages also recounted practices of neighboring communities based in values that differed their own, for example, Finney Farm's experience with the nearby church, as described above. Such instances underline differing community values, priorities, and perceptions about their identity, and therefore difficulties for initiating and maintaining external relationships. While this could point to a barrier for ecovillages' actions, it must also be recognized as an inevitable challenge in initiating greater-scale impact and change, especially in more mainstream society.

Nevertheless, all ecovillages researched actively attempted to be present and influence the public by acting as "demonstration projects" for mainstream society. For example, LAEV is intentionally socially and spatially integrated into their urban environment, and attempts to enhance local contact through involvement in their community. Their visibility increases the value of internal practices, modeling what is possible by "being the change they seek" (see also Ergas 2010, p. 40). Thus, practices occurring within the three ecovillages are intended to have further impact through trickling outside of the communities through such interactions. Similarly, communities' openness around their food practices enabled interaction 
and participation-witnessed by communities hosting public events and sharing resources with the public (ex. free seeds, access to the food lobby), which could indicate the communities' influence for their surrounding communities (cf. Westkog et al. 2019). However, food practices revealed nuances (i.e. internal tensions, contradictions, and competing visions) within these communities, including food purchasing decisions and perceptions of expansion. For example, public actions were not always received favorably within the ecovillages, as many residents saw these as impeding on their privacy. Such internal disagreements suggest tensions in ecovillages playing a potentially larger role in sustainability transformations and point to the compromises and flexibility that may be needed between collective actions and individual views.

Additionally, place-based food knowledge was essential for communities' internal food practices as well as a wider impact on sustainable food systems. Findings revealed that ecovillages accumulated knowledge and competencies (ex. about place-adapted seed varieties), which were enacted through collective practices (ex. gardening and saving seeds). Through then hosting public knowledgesharing events (ex. workshops and conferences), ecovillages expanded their network and developed themselves as social hubs. Meaning, the ecovillages are strongly nested within their larger community, and play a role in accumulating and disseminating knowledge and competencies around sustainable food practices. Similar to Calvet-Mir et al.'s (2016) findings of local ecological knowledge's transmission through home gardens, ecovillages' physical and social place played a vital role in exchanging knowledge.

The prominence of knowledge exchange activities, such as workshops, internships, and trainings, highlights the value of ecovillages for sharing different kinds of, perhaps innovative, knowledge beyond their immediate community. This research witnessed ecovillages open to the broader public to provide such services, as well as to specifically promote and teach their sustainable food practices, which were often later applied by individuals outside of the community. The relevance of sharing such knowledge on e.g. food processing is heightened by "deskilling" witnessed in modern unsustainable agro-food systems (Jaffe and Gertler 2006). Offering a physical and social place to exchange knowledge alternative to mainstream discourses "represent[s] a challenge to dominant development trajectories and to conservative doctrines of necessity and inevitability" (Jaffe and Gertler 2006, p. 158). Results illustrate that, through providing such a place, ecovillages confront conventional knowledge, and support knowledge around sustainable place-based practices. Knowledge sharing is therefore one way in which ecovillages highlight the importance of relational networks and place for contributing to food sustainability.

\section{Ecovillage foodscapes and sustainable food systems}

Foodscapes illuminates a landscape of interconnected food practices. Sustainable food systems emphasize a place-based approach, with shorter physical and mental distances, and the connecting and intertwining of practices around social and environmental care. Employing the foodscapes lens at ecovillages highlights how communities oriented around sustainability utilize their social and spatial resources to craft places that foreground these values, for example being resourceful and integrating food into living environments (Ulug and Horlings 2019). Furthermore, what this paper contributes is evidence of the added value of the interconnected and relational networks for sustainable food system change.

Viewing ecovillage food practices in relation to their wider communities, through the foodscapes lens, supports place not being limited to the local context (Born and Purcel 2006; Kenis and Mathijs 2014). Through food practices, we see how ecovillages are embedded in external communities as resources centers, with their place-based quality simultaneously employed to enact change at a greater scale. Therefore, the foodscapes lens aligns with the relational perspective of place, which contends that it is "in and across places that food actors come together" (Sonnino et al. 2016, p. 486). That being said, we also recognize that, similar to local (Born and Purcel 2006; Kenis and Mathijs 2014), place-based food practices and food systems are not, by default, sustainable. Rather, the focus on " 'place' brings to the fore a more nuanced emphasis on the socio-environmental specificities of food and agriculture," also helping trace resources, knowledge, and meanings (Lever et al. 2019, p. 98). For example, in Los Angeles, water travels for hundreds of miles, making many forms of water-intensive agriculture unsustainable (Pincetl et al. 2016). Tracing such practices and resources can help inspire creative sustainable alternatives, such as installing gray water irrigation systems, as seen at LAEV. This article highlights how places are embedded with implications. While the ecovillages researched are open to public visits and interactions, they potentially present accessibility barriers for those with diverging values or lifestyles. Therefore, through the foodscapes lens' focus on social relations, we can better highlight such nuances and better ground sustainability impacts in concrete practices, also following from Robertson (2018).

Throughout this paper we have illustrated the value of the foodscapes lens to better understand the role of ecovillages for sustainable food systems. Using the foodscapes lens, we frame ecovillages' sustainability impacts across scales, connecting local community action to globallyscaled issues. For example, at Twin Oaks, residents used place-based resources to address the external issue of food waste in a nearby town. While food waste can be linked 
to overproducing global economic systems (Holt-Giménez 2017), it manifests on a local level and can inspire local action (Ulug and Trell 2020), also breaking down dualisms between a simply "global" or "local" food system (Hinrichs 2015; Morgan et al. 2006). The initiatives in this paper show communities taking on action, with impacts that echo across different levels in their food system.

Furthermore, the foodscapes lens foregrounds, not only food's relationships with place, but also the encompassing multi-scalar systems and institutions (Miewald and McCann 2014). Transitioning to a sustainable food system is argued to necessitate a transformation of power relations and political participation, towards more democratic forms (Blythe et al. 2018; De Schutter et al. 2019; Hassanein 2003). Ecovillages, which have a potentially confronting relationship with their surrounding communities, are useful to illustrate such interactions, seen, for example, with the creeping changes towards the mainstream at Twin Oaks and the neighborhood dynamics at LAEV. Recognizing how environmental change is intertwined with social struggles (Swyngedouw and Heynen 2003), the foodscapes lens highlights how food and social relationships are tied to place, to help provide a more nuanced understanding of sustainable food system change, one where the material resources as well as the social dynamics play a role.

Ecovillages are an example of how to expand the space for adaptation, through sustaining resourceful environments, bringing small-scale practices and initiatives to fruition, and expanding their reach. Examining community practices provides an understanding of the place-based context where they materialize. Drawing out specific elements lends insight into how practices can be translated to and influence more mainstream society. That being said, this research does not envision ecovillages as a catchall solution, rather, a source of inspiration and insight into how resourceful collective practices contribute towards more sustainable societies. Furthermore, while this research focuses on one practice in each community, we also witnessed many food practices which did not extend beyond the ecovillage context, for example, garden produce, which was largely consumed internally. Interviewees emphasized that their community food practices often mirrored daily community operations and processes, with their internal food systems reflecting the self-reliance and autonomy of their community. However, participants acknowledged challenges for navigating and engaging with globally-scaled food systems, to ultimately initiate a transformational food system beyond self-sufficiency.

Throughout this research, many themes arose beyond the scope of this article, which we hope will be incorporated into future research. Foremost, we found many contradictions between community members' identity and ecovillages' goals towards more sustainable food systems and societies, briefly touched upon in this paper. These could be challenges to communities' attempts towards wider-scale transformation and should therefore be further researched.

Through combining the foodscapes lens and SPT, this research explored food practices at ecovillage communities and unearthed how food, not only bridges ecovillages with more mainstream society, but also illuminates how ecovillages are fertile ground for developing sustainable food systems and societies.

Acknowledgements The authors would like to thank all of the research participants for enthusiastically taking part in the data collection and patiently donating their time and energy.

Open Access This article is licensed under a Creative Commons Attribution 4.0 International License, which permits use, sharing, adaptation, distribution and reproduction in any medium or format, as long as you give appropriate credit to the original author(s) and the source, provide a link to the Creative Commons licence, and indicate if changes were made. The images or other third party material in this article are included in the article's Creative Commons licence, unless indicated otherwise in a credit line to the material. If material is not included in the article's Creative Commons licence and your intended use is not permitted by statutory regulation or exceeds the permitted use, you will need to obtain permission directly from the copyright holder. To view a copy of this licence, visit http://creativecommons.org/licenses/by/4.0/.

\section{References}

Adema, P. 2007. Foodscape: An emulsion of food and landscape. Gastronomica 7 (1): 1-5.

Agyeman, J., R.D. Bullard, and B. Evans. 2002. Exploring the nexus: Bringing together sustainability, environmental justice and equity. Space and Polity 6 (1): 77-90.

Appadurai, A. 1990. Disjuncture and difference in the global cultural economy. Theory, Culture and Society 7: 295-310.

Avelino, F. and I. Kunze. 2009. Exploring the transition potential of the Ecovillage Movement. invited keynote lecture and paper. In Presented at European conference on sustainability transitions: Dynamics and governance of transitions to sustainability, Amsterdam, The Netherlands, 4-5 June 2009.

Blay-Palmer, A., and M. Koc. 2010. Imagining sustainable food systems: The path to regenerative food systems. In Imagining sustainable food systems: Theory and practice, ed. A. Blay-Palmer, 168-186. London: Routledge.

Blythe, J., J. Silver, L. Evans, D. Armitage, M. Moore, T. Morrison, and K. Brown. 2018. The Dark side of transformation: Latent risks in contemporary sustainability discourse. Antipode 50 (5): 1206-1223.

Born, B., and M. Purcell. 2006. Avoiding the local trap: Scale and food systems in planning research. Journal of Planning Education and Research 26: 195-207.

Boyer, R. 2015. Grassroots innovation for urban sustainability: Comparing the diffusion pathways of three ecovillage projects. Environment and Planning A 45: 320-337.

Brombin, A. 2015. Faces of sustainability in Italian ecovillages: Food as a 'contact zone.' International Journal of Consumer Studies 39: $468-477$. 
Burgoine, T., and P. Monsivais. 2013. Characterizing food environment exposure at home, at work, and along commuting journeys using data on adults in the UK. International Journal of Behavioral Nutrition and Physical Activity 10 (85): 1-11.

Calvet-Mir, L., C. Riu-Bosoms, M. González-Puente, I. Ruiz-Mallén, V. Reyes-García, and J. Luis Molina. 2016. The transmission of home garden knowledge: Safeguarding biocultural diversity and enhancing social-ecological resilience. Society and Natural Resources 29 (5): 556-571.

Carolan, M.S. 2011. Embodied food politics. Surrey: Ashgate Publishing.

Chitewere, T. 2010. Equity in sustainable communities: Exploring tools for environmental justice and political ecology. Natural Resources Journal 50: 315-339.

Christian, D.L. 2003. Creating a life together: Practical tools to grow ecovillages and intentional communities. Gabriola Island: New Society Publishers.

Cook, I., et al. 2006. Geographies of food: Following. Progress in Human Geography 30 (5): 655-666.

Daly, M. 2017. Quantifying the environmental impact of ecovillages and co-housing communities: A systematic literature review. Local Environment 22 (11): 1358-1377.

De Schutter, O., U. Mattei, J.L. Vivero-Pol, and T. Ferrando. 2019. Towards a new relationship between the public, the civic and the private. In Routledge handbook of food as a commons, ed. J.L. Vivero-Pol, T. Ferrando, O. De Schutter, and U. Mattei, 373-395. London: Routledge.

Eakin, H., J.P. Connors, C. Wharton, F. Bertmann, A. Xiong, and J. Stoltzfus. 2017. Identifying attributes of food system sustainability: Emerging themes and consensus. Agriculture and Human Values 34: 757-773.

Ergas, C. 2010. A model of sustainable living: Collective identity in an urban ecovillage. Organization and Environment 23 (1): 32-54.

Erickson, P. 2008. Conceptualizing food systems for global environmental change research. Global Environmental Change 18: 234-245.

Feagan, R. 2007. The place of food: mapping out the 'local' in local food systems. Progress in Human Geography 31 (1): 23-42.

Feenstra, G. 2002. Creating space for sustainable food systems: Lessons from the field. Agriculture and Human Values 19: 99-106.

Feola, G. 2015. Societal transformation in response to global environmental change: A review of emerging concepts. Ambio 44 (5): 376-390.

Firth, C., D. Maye, and D. Pearson. 2011. Developing "community" in community gardens. Local Environment 16 (6): 555-568.

Forde, E. 2017. The ethics of energy provisioning: Living off-grid in rural Wales. Energy Research and Social Science 30: 82-93.

Fotopoulos, T. 2000. The limitations of life-style strategies: The Ecovillage 'Movement' is NOT the way towards a new democratic society. Democracy and Nature 6 (2): 287-308.

Fuster, M. 2017. "We like Fried Things": Negotiating health and taste among Hispanic Caribbean Communities in New York City. Ecology of Food and Nutrition 56 (2): 124-138.

Geyzen, A., P. Scholliers, and F. Leroy. 2012. Innovative traditions in swiftly transforming foodscapes: An exploratory essay. Trends in Food Science and Technology 25: 47-52.

Gillman, R. 1991. The ecovillage challenge. In Context 29: 10-14.

Goodman, D., and M. DuPuis. 2002. Knowing and growing food: Beyond the production-consumption debate in the sociology of agriculture. Sociologia Ruralis 42 (1): 6-23.

Grin, J. 2011. Changing governments, kitchens, supermarkets, firms and farms. In Food practices in transition, ed. G. Spaargaren, P. Oosterveer, and A. Loeber, 35-59. New York: Routledge.
Guthman, J. 2003. Fast food/organic food: Reflexive tastes and the making of 'yuppie chow.' Social and Cultural Geography 4 (1): $45-58$.

Hassanein, N. 2003. Practicing food democracy: A pragmatic politics of transformation. Journal of Rural Studies 19: 77-86.

Hassink, J., A. Moriggi, S. Senni, E. Hense, and D. de Moor. 2002. Caring agriculture and food practices. In Routledge handbook of sustainable and regenerative food systems, ed. J. Duncan, M. Carolan, and J. Wiskerke, 126-140. London: Routledge.

Heatherington, T. 2014. Tasting cultural ecology: Foodscapes of sustainability in the Mediterranean. Gastronomica 14 (2): 16-26.

Helicke, N.A. 2015. Seed exchange networks and food system resilience in the United States. Journal of Environmental Studies and Sciences 5: 636-649.

Hesse-Biber, S.N., and P. Leavy. 2004. Approaches to qualitative research. New York: Oxford University Press.

Hinrichs, C. 2015. Fixing food with ideas of 'local' and 'place.' Journal of Environmental Studies and Sciences 6 (4): 759-764.

Holt-Giménez, E. 2017. A foodie's guide to capitalism. New York: Monthly Review Press.

Horlings, L.G. 2018. Politics of connectivity: The relevance of placebased approaches to support sustainable development and the governance of nature and landscape. In The SAGE handbook of nature, ed. T. Marsden, 304-324. London: SAGE Publications, Inc.

Jaffe, J., and M. Gertler. 2006. Victual vicissitudes: Consumer deskilling and the (gendered) transformation of food systems. Agriculture and Human Values 23: 143-162.

Johnston, J., and M.K. Goodman. 2015. Spectacular foodscapes: Food celebrities and the politics of lifestyle mediation in an age of inequality. Food Culture and Society 18 (2): 205-222.

Kanter, R.M. 1972. Commitment and community. Cambridge: Harvard University Press.

Kasper, C., J. Brandt, K. Lindschulte, and U. Giseke. 2017. The urban food system approach: Thinking in spatialized systems. Agroecology and Sustainable Food Systems 41 (8): 1009-1025.

Kaufman, J. 2018. Hippie food: How back-to-the-landers, longhairs, and revolutionaries changed the way we eat. New York: William Morrow.

Kenis, A., and E. Mathijs. 2014. De)politicising the local: The case of the Transition Towns Movement in Flanders (Belgium. Journal of Rural Studies 34: 172-183.

Kwik, J. 2008. Traditional food knowledge: A case study of an immigrant Canadian "foodscape." Environments 36 (1): 59-74.

Leitheiser, S., and A. Follman. 2019. The social innovation-(re)politicisation nexus: Unlocking the political in actually existing smart city campaigns? The case of Smart City Cologne, Germany. Urban Studies 57 (4): 894-915.

Lever, J., R. Sonnino, and F. Cheetham. 2019. Reconfiguring local food governance in an age of austerity: Towards a place- based approach? Journal of Rural Studies 69: 97-105.

Litfin, K.T. 2014. Ecovillages: Lessons for sustainable community. Malden: Polity Press.

Lockyer, J. 2007. Sustainability and utopianism: An ethnography of cultural critique in contemporary intentional communities. PhD Dissertation, University of Georgia in Athens.

Madrigal, T. 2017. "We are human!": Farmworker organizing across the food chain in Washington. In Mexican-origin foods, foodways, and social movements, ed. D. Peña, L. Calvo, P. McFarland, and G. Valle, 251-290. Fayetteville: University of Arkansas Press.

Massey, D. 1991. A global sense of place. Marxism Today 38: 24-29.

Meijering, L., P. Huigen, and B. van Hoven. 2007. Intentional communities in rural spaces. Tijdschrift voor Economische en Sociale Geografie 98 (1): 42-52. 
Miewald, C., and E. McCann. 2014. Foodscapes and the geographies of poverty: Sustenance, strategy, and politics in an urban neighborhood. Antipode 46 (2): 537-556.

Mikkelson, B.E. 2011. Images of foodscapes: Introduction to foodscape studies and their application. Perspectives in Public Health 131 (5): 209-216.

Moragues-Faus, A., and R. Sonnino. 2019. Re-assembling sustainable food cities: An exploration of translocal governance and its multiple agencies. Urban Studies 56 (4): 778-794.

Morgan, K., and R. Sonnino. 2010. The urban foodscape: World cities and the new food equation. Cambridge Journal of Regions, Economy and Society 3: 209-224.

Morgan, K., T. Marsden, and J. Murdoch. 2006. Worlds of food: Place, power and provenance in the food chain. Oxford: Oxford University Press.

Nestle, M. 2002. Food politics: How the food industry influences nutrition and health. Berkeley: University of California Press.

Nicolini, D. 2012. Practice theory, work, and organization: An introduction. Oxford: Oxford University Press.

Panelli, R. and G. Tipa. 2009. Beyond foodscapes: Considering geographies of Indigenous well-being. Health and Place 15: 455-465.

Pew Research Center. 2019. Political polarization in the American public. Pew Research Center. https://www.people-press.org/2014/06/ 12/political-polarization-in-the-american-public/. Accessed 8 Nov 2019.

Pincetl, S., E. Porse, and D. Cheng. 2016. Fragmented flows: Water supply in Los Angeles County. Environmental Management 58: 208-222.

Psarikidou, K., and B. Szerszynski. 2012. Growing the social: Alternative agrofood networks and social sustainability in the urban ethical foodscape. Sustainability: Science, Practice and Policy 8 (1): 30-39.

Pudup, M. 2008. It takes a garden: Cultivating citizen-subjects in organized garden projects. Geoforum 39: 1228-1240.

Reckwitz, A. 2002. Toward a theory of social practices: A development in culturalist theorizing. European Journal of Social Theory 5 (2): 243-263.

Renting, H., T.K. Marsden, and J. Banks. 2003. Understanding alternative food networks: Exploring the role of short food supply chains in rural development. Environment and Planning A 35: 393-411.

Robertson, S. 2018. Rethinking relational ideas of place in more-than human cities. Geography Compass 12 (4): 1-12.

Schatzki, T. 1996. Social practices: a Wittgensteinian approach to human activity and the social. Cambridge: Cambridge University Press.

Schehr, R.C. 1997. Dynamic utopia: Establishing intentional communities as a new social movement. Westport: Bergin and Garvey.

Sharp, E.L. 2017. (Re)assembling foodscapes with the Crowd Grown Feast. Area 50 (2): 1-7.

Shove, E., and G. Walker. 2010. Governing transitions in the sustainability of everyday life. Research Policy 39: 471-476.

Shove, E., M. Pantzar, and M. Watson. 2012. The dynamics of social practice. London: Sage Publications.

Smith, J., and P. Jehlička. 2007. Stories around food, politics and change in Poland and the Czech Republic. Transactions of the Institute of British Geographers 32 (3): 395-410.

Sonnino, R., T. Marsden, and A. Moragues-Faus. 2016. Relationalities and convergences in food security narratives: Towards a place-based approach. Transactions of the Institute of British Geographers 41: 477-489.

Sonnino, R., and T. Marsden. 2006. Beyond the divide: Rethinking relationships between alternative and conventional food networks in Europe. Journal of Economic Geography 6 (2): 181-199.

Spaargaren, G., P. Oosterveer, and A. Loeber. 2013. Sustainability transitions in food consumption, retail and production. In Food practices in transition, ed. G. Spaargaren, P. Oosterveer, and A. Loeber, 1-31. London: Routledge.
Spijker, S.N., E. Mathijs, and C. Parra. 2020. Grasping practices of selfreliance within alternative foodscapes in Flanders. Agriculture and Human Values 37: 819-832.

Swagemakers, P., M.D. Domínguez García, P. Milone, F. Ventura, and J.S.C. Wiskerke. 2019. Exploring cooperative place-based approaches to restorative agriculture. Journal of Rural Studies 68: 191-199.

Swenson, D. 2019. Most of America's rural areas are doomed to decline. The Conversation. http://theconversation.com/most-of-americasrural-areas-are-doomed-to-decline-115343. Accessed 8 Nov 2019.

Swyngedouw, E., and N. Heynen. 2003. Urban political ecology, justice and the politics of scale. Antipode 35 (5): 898-918.

Trell, E., and B. Van Hoven. 2010. Making sense of place: Exploring creative and (inter)active research methods with young people. Fennia 188 (1): 91-104.

Tremblay, E., A. Hupper, and T. Waring. 2019. Co-operatives exhibit greater behavioral cooperation than comparable businesses: Experimental evidence. Journal of Co-operative Organization and Management 7 (2): 100092.

Ulug, C., and L.G. Horlings. 2019. Connecting resourcefulness and social innovation: Exploring conditions and processes in community gardens in the Netherlands. Local Environment 24 (3): 147-166.

Ulug, C., and E.M. Trell. 2020. "It's not really about the food, it's also about food": Urban collective action, the community economy and autonomous food systems at the Groningen Free Café. International Journal of Urban Sustainable Development 12 (2): 127-142.

Vinnari, M., and E. Vinnari. 2014. A framework for sustainability transition: The case of plant-based diets. Journal of Agricultural and Environmental Ethics 27 (3): 369-396.

Vivero-Pol, J., T. Ferrando, O. De Schutter, and U. Mattei. 2019. Routledge handbook of food as a commons. London: Routledge.

Wagner, F. 2012. Ecovillage research review. In Realizing utopia: Ecovillage endeavors and academic approaches, ed. M. Andreas and F. Wagner, 81-94. Munich: Rachel Carson Center.

Warde, A. 2013. What sort of practice is eating. In Sustainable practices: Social theory and climate change, ed. N. Spurling and E. Shove, 17-30. New York: Routledge.

Wegerif, M., and J. Wiskerke. 2017. Exploring the staple foodscape of Dar es Salaam. Sustainability 9: 1-16.

Westkog, H., T. Winther, and M. Aasen. 2019. The creation of an Ecovillage: Handling identities in a Norwegian Sustainable Valley. Sustainability 10 (2074): 1-20.

Wight, R.A., and J. Killham. 2014. Food mapping: A psychogeographical method for raising food consciousness. Journal of Geography in Higher Education 38 (2): 314-321.

Wingeyer, A.B., T.J.C. Amado, M. Pérez-Bidegain, A.G. Studdert, C.H. Perdomo Varela, F.O. Garcia, and D.L. Karlen. 2017. Soil quality impacts of current South American agricultural practices. Sustainability. 7: 2213-2242.

Winson, A. 2004. Bringing political economy into the debate on the obesity epidemic. Agriculture and Human Values 21: 299-312.

Wiskerke, J.S.C. 2009. On places lost and places regained: Reflections on the alternative food geography and sustainable regional development. International Planning Studies 14 (4): 369-387.

Yasmeen, G. 1996. "Plastic-bag housewives" and postmodern restaurants? Public and private in Bangkok's foodscape. Urban Geography 17 (6): 526-544.

Publisher's Note Springer Nature remains neutral with regard to jurisdictional claims in published maps and institutional affiliations.

Ciska Ulug is a PhD Candidate in the Department of Spatial Planning and Environment at the University of Groningen, The Netherlands. Her $\mathrm{PhD}$ research looks at the role of community-based food collectives 
for greater food system sustainability, with case studies also looking at a food waste initiative and community gardens (in the Netherlands). Other research interests include community and diverse economies, food sovereignty, and community resourcefulness.

Elen-Maarja Trell is Assistant Professor in Spatial Planning and Environment at the University of Groningen, the Netherlands. Her research focuses on the role of collective action in creating more resilient, sustainable, and inclusive places. Specific themes include agro-food movements, community resilience to flooding, community resilience in rural areas, and climate change adaptation.

Lummina Horlings is Professor in Socio-spatial Planning at the University of Groningen, The Netherlands. She is interested in how people collectively shape sustainable places together, how they take the lead in this, and why. 